\title{
The Characteristics of Pruritus in Thai Type2 Diabetic Patients and its Impact on their Dermatology Life Quality Index
}

\author{
Metavee Boonsiri* and Sophon Duangthipnate \\ Dermatology Unit, Faculty of Medicine, Vajira Hospital, Navamindradhiraj University, Thailand
}

*Corresponding author: Metavee Boonsiri, Dermatology Unit, Faculty of Medicine, Vajira Hospital, Navamindradhiraj University, Thailand

\section{ARTICLE INFO}

Received: 䋲 December 16, 2019

Published: 蔧January 06, 2020

Citation: Metavee Boonsiri, Sophon Duangthipnate. The Characteristics of Pruritus in Thai Type2 Diabetic Patients and its Impact on their Dermatology Life Quality Index. Biomed J Sci \& Tech Res 24(2)-2020. BJSTR. MS.ID.004027.

Keywords: DM; DLQI; Pruritus

Abbreviations: T2DM: Type 2 Diabetes Mellitus; DLQI: Dermatology Life Quality Index; NRS: Numeric Rating Scale

\section{ABSTRACT}

Background: Dermatological manifestations in diabetes mellitus include those due to disease itself, as well as complications and their respective treatments. Pruritus often presents with cutaneous manifestations, causing psychological distress and leading to scratching. Data showing an association between pruritus and health-related quality of life in Thai type-2 DM (T2DM) patients are still lacking. Our study concerns itself with effects of type-2 DM in an urban area, and ways to improve the physical and psychological quality of life of patients.

Objectives: The purpose of the present study was to evaluate the dermatologic quality of life among Thai T2DM patients with pruritus, and the association between plasma glucose level and degree of itching.

Materials and Methods: The study included Thai T2DM patients with pruritus, aged 18 years or above, and who attended the outpatient DM Clinic at Vajira Hospital. Their previous plasma glucose, $\mathrm{HbA1C}$ level and personal histories were recorded. They were also asked to complete the questionnaire regarding Dermatologic Life Quality Index and Itching Numeric Sating Scale.

Results: 300 T2DM patients with pruritus were enrolled in this study. The average plasma glucose level was $160 \mathrm{mg} / \mathrm{dL}$, and HbA1C level was 7.9\%. We found no specific area of pruritus and most of the people have pruritus in more than one area. Most of our subjects have a mild to moderate degree of pruritus. Our study found that serum HbA1C levels above 6.5\%, and previous topical steroid and topical moisturizer no usage were significantly associated with pruritus. We found that dry skin and sweating were statistically aggravating factors after multivariate analysis. There is a strong association between education, marital status and DLQI score.

Conclusion: Our study found that the control of HbA1C level, and no usage of topical steroids and moisturizers were statistically associated with clinical pruritus. Although our study showed that pruritus had small effects on quality of life, we also found that moisturizer usage significantly helps to improve clinical pruritus. Thus, giving moisturizer to all T2DM patients may help to improve and prevent their pruritus symptoms.

\section{Short Communication}

Type 2 diabetes mellitus (T2DM) is a major health problem in Thailand. Nowadays, up to 800 patients per month register in Thai DM clinics to follow up their illness. T2DM systematically affects the body in both long-term and short-term outcomes [1,2]. Longterm effects of T2DM cause serious common consequences such as diabetic retinopathy, peripheral neuropathy, diabetic nephropathy, 
and diabetic dermopathy, while short-term effects cause troublesome symptoms such as fatigue, abnormal weight change, and insomnia. These symptoms are known to adversely affect patients' quality of life and mental health [1-3]. Dermatological manifestations in diabetes mellitus are due to disease itself, complications and their treatments. Dermatologic lesions associated with diabetes mellitus are classified into disease specific and non-specific symptoms. Consequences of neurovascular complications such as macroangiopathy, microangiopathy, and diabetic neuropathy are also formed [4-6].

Diabetic treatments can cause various dermatologic lesions. Treatment with insulin can cause allergic reactions, lipoatrophy, and insulin edema $[5,6]$. It has also been found that some conditions are associated with diabetics than nondiabetics such as lichen planus, eruptive xanthomas, perforating dermatosis, vitiligo, and yellow nails $[5,6]$. Pruritus, or itching, involves cutaneous manifestations over extended periods and often causes patients psychological distress, and causes which leads to skin infection $[7,8]$. Common causes of pruritus in dermatological conditions are atopic dermatitis, urticaria, psoriasis, and insect bite. However, systemic medical conditions include chronic renal failure, jaundice, chronic hepatitis, diabetes mellitus, and thyrotoxicosis [9-12] To our knowledge, there are some studies about the association between plasma glucose level and pruritus. They found that higher plasma glucose levels are significantly associated with a greater prevalence of pruritus in T2DM patients [9].

T2DM is associated with quality of life in many areas such as family, daily life, and self-esteem [13]. Histamine level is associated with pruritus; hence, antihistamines are considered to play a role in the reduction of itching. However, there is no standard treatment guideline for regularly using antihistamine in T2DM patients [1416]. Nevertheless, the data for an association between pruritus and health-related quality of life in Thai T2 DM patients are still lacking. Therefore, the purpose of our study was to evaluate the dermatology quality of life among Thai T2DM patients with pruritus and the association between plasma glucose level and degree of itching using Dermatology Life Quality Index (DLQI) questionnaires and the Itching Numeric Rating Scale (NRS) $[17,18]$. The factors considered included age, gender, educational degree, and duration of type 2 DM [1].

\section{Materials and Methods}

This study was approved by Vajira Hospital Institutional Review Board. The study design was a prospective descriptive study. Thai T2DM patients with pruritus, aged 18 years over, and who attended the out-patient DM Clinic at Vajira were included in the study. All of the other causes of pruritus (atopic dermatitis, urticaria, psoriasis, cutaneous fungal infection, contact dermatitis) and the other systemic conditions associated with pruritus such as chronic renal failure, jaundice, chronic hepatitis, thyrotoxicosis, and hematologic malignancy were excluded from the study.

\section{Statistical Analysis}

All analyses were performed by using SPSS software version 22.0. Continuous data were described as mean and standard deviation. The statistical comparisons of the DLQI results between subpopulations were performed by using Fisher's exact test and Mann-Whitney U Test. A p-value $<0.05$ was considered statistically significant. Correlation analysis was made by using Spearman's Correlation Test [19-21].

\section{Results}

Of the 300 patients enrolled, 177 patients were female, and the rest were male. Table 1 shows demographic data in patients studied. Almost half of them were unemployed. More than fifty percent of them were married and living with their spouse. One hundred and fifty-nine patients graduated from primary school. The average duration for having DM was nine years, and the average plasma glucose level was $160 \mathrm{mg} / \mathrm{dL}$ while average HbA1C level is 7.9\%. Table 2 shows the characteristics of pruritus in our patients studied. We found no specific area of pruritus and most of the people have pruritus in more than one area. Approximately forty percent of the patients mentioned that head, neck, body, and lower extremities are the most itch areas, while upper extremities are less affected. After univariate and multivariate analysis, our study found that serum $\mathrm{HbA} 1 \mathrm{C}$ level above $6.5 \%$, no usage of topical steroids and topical moisturizer were significantly associated with pruritus, while anti-histamine usage, serum fasting plasma glucose $>126 \mathrm{mg} / \mathrm{dL}$, and having diabetes for over 10 years were not relevant factors in pruritus (Data shown in Table 3).

Table 1: Demographic data of subjects $(n=300)$.

\begin{tabular}{|c|c|c|}
\hline & No & $\%$ \\
\hline \multicolumn{3}{|c|}{ Gender } \\
\hline Male & 123 & $(41.0)$ \\
\hline Female & 177 & $(59.0)$ \\
\hline Age (Years Old) & \multicolumn{2}{|c|}{$63.80 \pm 12.67$} \\
\hline \multicolumn{3}{|c|}{ Occupation } \\
\hline No occupation & 138 & $(46.0)$ \\
\hline Employee & 66 & $(22.0)$ \\
\hline Government officer & 33 & $(11.0)$ \\
\hline Own business & 45 & $(15.0)$ \\
\hline Retired & 15 & $(5.0)$ \\
\hline Others & 3 & $(1.0)$ \\
\hline \multicolumn{3}{|c|}{ Educations } \\
\hline No education & 13 & $(4.3)$ \\
\hline Primary school & 159 & $(53.0)$ \\
\hline Secondary school & 82 & $(27.3)$ \\
\hline Bachelor or above & 46 & $(15.3)$ \\
\hline \multicolumn{3}{|c|}{ Marital Status } \\
\hline Married and living together & 158 & $(52.7)$ \\
\hline Married but not living together & 11 & $(3.7)$ \\
\hline Single & 65 & $(21.7)$ \\
\hline Divorced & 3 & $(1.0)$ \\
\hline
\end{tabular}


Table 2: Characteristics of pruritus of subjects $(n=300)$.

\begin{tabular}{|c|c|c|}
\hline \multicolumn{2}{|c|}{ Pruritus Data } & $(45.0)$ \\
\hline Head, Face, and neck & 135 & $(45.0)$ \\
\hline Torso & 135 & $(41.3)$ \\
\hline Thigh, leg and foot & 124 & $(5.4)$ \\
\hline Arm, forearm, and hand & 16 & $(21.3)$ \\
\hline Topical Medication & 64 & $(10.33)$ \\
\hline Topical corticosteroid (NO) & 31 & $(9.3)$ \\
\hline Moisturizer (NO) & 28 & $(7.0)$ \\
\hline Oral medication used & 21 & $(5.66)$ \\
\hline Oral antihistamine & 17 & $(1.6)$ \\
\hline Other & 5 & \\
\hline
\end{tabular}

Data are presented as $\mathrm{n}(\%)$

Table 3: The association of pruritus with relevant factors.

\begin{tabular}{|c|c|c|c|c|c|c|}
\hline \multirow{2}{*}{ Factors } & \multicolumn{3}{|c|}{ Univariable Analysis } & \multicolumn{3}{|c|}{ Multivariable Analysis } \\
\hline & OR & $95 \% \mathrm{CI}$ & p-value & $\mathbf{O}_{\text {Radj }}$ & $95 \% \mathrm{CI}$ & p-value \\
\hline $\begin{array}{l}\text { Duration of DM (yrs) } \\
\qquad<10 \\
\geq 10\end{array}$ & 1.96 & $(0.83-4.62)$ & 0.126 & 1.70 & $(0.67-4.30)$ & 0.265 \\
\hline $\begin{array}{c}\text { FBS } \\
\leq 126 \mathrm{mg} / \mathrm{dl} \\
>126 \mathrm{mg} / \mathrm{dl}\end{array}$ & 0.91 & $(0.37-2.20)$ & 0.826 & 1.39 & $(0.51-3.74)$ & 0.519 \\
\hline $\begin{array}{l}\text { HbA1c } \\
<6.5 \% \\
\geq 6.5 \% \\
\end{array}$ & 0.20 & $(0.08-0.49)$ & $<0.001$ & 0.20 & $(0.08-0.52)$ & 0.001 \\
\hline $\begin{array}{c}\text { Topical Steroid } \\
\text { No } \\
\text { Yes }\end{array}$ & 4.93 & $(1.6-15.13)$ & 0.005 & 4.21 & $(1.17-15.11)$ & 0.027 \\
\hline $\begin{array}{l}\text { Moisturizer } \\
\text { No } \\
\text { Yes }\end{array}$ & 3.85 & $(1.39-10.69)$ & 0.010 & 3.93 & $(1.32-11.72)$ & 0.014 \\
\hline $\begin{array}{c}\text { Oral Antihistamine } \\
\text { No } \\
\text { Yes }\end{array}$ & 1.48 & $(0.32-6.84)$ & 0.618 & 1.26 & $(0.22-7.30)$ & 0.797 \\
\hline
\end{tabular}

Table 4 shows the numeric rating scale in each range and average score. Our study shows VAS mean score were3.15 \pm 1.93 . of our subjects had a mild to moderate degree of pruritus. Table 5 shows associated factors that affect pruritus. We found that dry skin, sweating, and cold weather were statistically aggravating factors (when using univariate analysis; p-value $<0.05$ ). However, cold weather is not statistically significant after multivariable analysis. Table 6 shows DLQI score in our patients studied. Our study found that the mean DLQI score is 1.98. More than half of our subject responded that their quality of life was not affected by pruritus [22].
Table 4: Itching Numeric rating scale.

\begin{tabular}{|c|c|c|}
\hline \multicolumn{2}{|c|}{ Itching Numeric Rating Scale } \\
\hline VAS mean score & $3.15 \pm 1.93$ & \\
\hline \multicolumn{3}{|c|}{ Score } \\
\hline $0.0-2.9$ (Mild) & 129 & $(43.0)$ \\
\hline $3.0-6.9$ (Moderate) & 147 & $(49.0)$ \\
\hline $7.0-8.9$ (Severe) & 17 & $(5.7)$ \\
\hline $9.0-10.0$ (Very severe) & 7 & $(2.3)$ \\
\hline
\end{tabular}

Data are presented as $\mathrm{n}(\%)$ or mean \pm SD. 
Table 5: Univariable and multivariable analysis of factors associated with pruritus.

\begin{tabular}{|c|c|c|c|c|c|c|}
\hline \multirow{2}{*}{ Factors } & \multicolumn{3}{|c|}{ Univariable analysis } & \multicolumn{3}{|c|}{ Multivariable analysis } \\
\cline { 2 - 7 } & $\mathbf{O R}$ & $\mathbf{9 5 \% C I}$ & $\mathbf{p}$-value & $\mathbf{0}_{\text {Radj }}$ & $\mathbf{9 5 \% C I}$ & $\mathbf{p}$-value \\
\hline Stress & 1.93 & $(0.43-8.69)$ & 0.390 & 0.70 & $(0.12-4.27)$ & 0.703 \\
\hline Dry skin & 3.23 & $(1.69-6.19)$ & $<0.001$ & 2.14 & $(1.01-4.57)$ & 0.048 \\
\hline Warm bathe & 2.20 & $(0.83-5.84)$ & 0.113 & 1.56 & $(0.53-4.58)$ & 0.420 \\
\hline Cold bathe & 3.11 & $(0.40-24.36)$ & 0.281 & 1.53 & $(0.17-13.54)$ & 0.704 \\
\hline Sweating & 6.06 & $(2.85-12.86)$ & $<0.001$ & 5.78 & $(2.67-12.51)$ & $<0.001$ \\
\hline Cold weather & 3.14 & $(1.08-9.12)$ & 0.035 & 1.78 & $(0.56-5.71)$ & 0.330 \\
\hline Insomnia & 3.22 & $(0.74-14.03)$ & 0.119 & 1.95 & $(0.37-10.17)$ & 0.428 \\
\hline Exercise & - & - & NA & - & - & NA \\
\hline Natural Fabrics clothes & - & - & NA & - & NA \\
\hline Synthetic Fabrics clothes & - & - & NA & - & NA \\
\hline
\end{tabular}

Table 6: DLQI score in our patients studied.

\begin{tabular}{|c|c|c|}
\hline \multicolumn{3}{|c|}{ DLQI Score } \\
\hline DLQI score & $1.98 \pm 2.68$ & \\
\hline \multicolumn{3}{|c|}{ DLQI } \\
\hline No effect & 166 & $(55.3)$ \\
\hline Small effect & 117 & $(39.0)$ \\
\hline Moderate effect & 9 & $(3.0)$ \\
\hline Very large effect & 7 & $(2.3)$ \\
\hline Extremely large effect & 1 & $(0.3)$ \\
\hline
\end{tabular}

\section{Discussion}

Type-2 diabetes mellitus (T2DM) is a systematic disease, in which multiple organs are involved including the dermatological system. The effects of T2DM to dermatological problems come from the disease, complications, and the consequences of treatment [13]. Pruritus (itching) is one of the most common clinical symptoms. It often presents in T2DM patients with adverse effects on their quality of life and mental status [7]. Of all the systemic diseases associated with pruritus, renal failure is probably the most common underlying disease. In diabetes mellitus, generalized pruritus is rare but localized pruritus is more frequent, especially in the perianal/ genital region, and caused by fungal infection [23]. To date, there have been many studies about the association between plasma glucose level and pruritus $[9,13]$. They found that an elevated plasma glucose level is significantly associated with a greater prevalence of pruritus in T2DM patients $[9,13]$. Nevertheless, data for the association between pruritus and health-related quality of life in Asian T2DM patients are still lacking.

Our study showed that eighty percent of T2DM patients had mild to moderate pruritus (NRS 0.0 - 6.9). We found that most of them had clinical pruritus more to than one part of the body. The most affected areas were the face, torso, and lower extremities, while upper extremities were less affected. The diabetic profiles in our subjects were not well controlled. The average duration of having DM was nine years, average plasma glucose level was 160. Moreover, our study found that dry skin and sweating were statistically significant aggravating factors ( $p$-value<0.05). After multivariable analysis, it seems that serum $\mathrm{HbA1C}$ level, topical steroid no usage, and topical moisturizer no usage were associated with pruritus in our study ( $\mathrm{p}$-value<0.05). In poorly controlled T2DM. Dry skin is a well-known factor which aggravates itching, so topical moisturizer is commonly effective, thus explaining its association with pruritus. There were strong associations between education, marital status and DLQI score ( $\mathrm{p}$-value $<0.05$ ).

T2DM patients who have pruritus were affecting their quality of life. We found that mean DLQI score was 1.98, which means that pruritus has no, or a small, effect on their quality of life. Compared to other systemic diseases, our study had lower DLQI scores than others. Batalla et al. showed the DLQI in CLE had an extremely large effect on quality of life in more than half of the patients [24]. A study of DLQI in Thai patients with systemic sclerosis showed moderate impact on patients' dermatology-specific health-related quality of life, which is predominantly in pain and pruritus (mean DLQI score $=6.3$ ) [21]. Boonsiri et al. reported DLQI in Thai dialysis patients showing the large impact on their quality of life, in which xerosis and pruritus were the most significant problems (mean DLQI score $=4.74$ ) [12]. However, our study was done only in a government hospital. More than $40 \%$ of all patients had no job, and their education was below bachelor's degree level. The degree and frequency of dermatological involvement in T2DM disease, compared to other diseases such as ESRD, systemic sclerosis, and CLE seem to be less frequent. It means that dermatologic quality of life of individuals might vary due to socioeconomic, educational status, and specific systemic disease.

\section{Conclusion}

Our study found that the control of $\mathrm{HbA} 1 \mathrm{C}$ level, usage of topical steroids and moisturizers are statistically associated with clinical pruritus. Dry skin and sweating were statistically aggravating 
factors. Although our study found that pruritus had small effects on quality of life, we also found that use of topical steroids and moisturizers is significantly helps improve clinical pruritus. Thus, giving moisturizer to T2DM patients may help to improve and prevent their pruritus symptoms.

\section{References}

1. Trikkalinou A, Papazafiropoulou AK, Melidonis A (2017) Type 2 diabetes and quality of life. World J Diabetes 8(4): 120-129.

2. Papadopoulos AA, Kontodimopoulos N, Frydas A, Ikonomakis E, Niakas D (2007) Predictors of health-related quality of life in type II diabetic patients in Greece. BMC Public Health 7: 186.

3. Polonsky WH (2000) Understanding and Assessing Diabetes-Specific Quality of Life. Diabetes Spectrum 13(1): 36.

4. Chan JC, Malik V, Jia W, Kadowaki T, Yajnik CS, et al. (2009) Diabetes in Asia: epidemiology, risk factors, and pathophysiology. JAMA 301(20): 2129-2140.

5. Chilukuri S, Nikica C, Ivana PR (2002) Dermatologic lesions in diabetes mellitus. Dibetologia Croatica p. 31-33.

6. Tarikci N, Kocatürk E, Güngör Ş, Topal IO, Can PÜ, et al. (2015) Pruritus in Systemic Diseases: A Review of Etiological Factors and New Treatment Modalities. The Scientific World Journal 2015: 803752.

7. Yosipovitch G, David M (1999) The diagnostic and therapeutic approach to idiopathic generalized pruritus. Int J Dermatol 38(12): 881-887.

8. Zirwas MJ, Seraly MP (2001) Pruritus of unknown origin: A retrospective study. J Am Acad Dermatol 45(6): 892-896.

9. Etter L, Myers SA (2002) Pruritus in systemic disease: mechanisms and management Dermatol Clin 20(3): 459-472.

10. Ponticelli C, Bencini PL (1995) Pruritus in dialysis patients: a neglected problem. Nephrol Dial Transplant 10(12): 2174-2176.

11. Jones EA, Bergasa NV (1992) The pruritus of cholestasis and the opioid system. JAMA 268(23): 3359-3362.

12. Boonsiri M, Prompongsa S, Bunyaatavej S (2015) Dermatologic Life Quality Index in Thai Dialysis Patients with Cutaneous Manifestations: A Cross-Sectional Study and Review. Vajira Medical Journal 59(1): 11-20.

\section{ISSN: 2574-1241}

DOI: 10.26717/BJSTR.2020.24.004027

Metavee Boonsiri. Biomed J Sci \& Tech Res

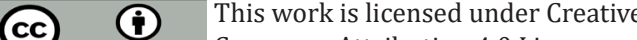
Commons Attribution 4.0 License

Submission Link: https://biomedres.us/submit-manuscript.php
13. Puavilai A, Stuifbergen AK (2000) Quality of life for Thai women with diabetes. Health Care Women Int 21(6): 471-483.

14. Bhate V, Abhayankar S (2014) Health related quality of life in type 2 diabetic patients with special emphasis on gender and mode of treatment. Indian Journal of Health and Wellbeing 5(3): 350-353.

15. Rajagopalan M, Saraswat A, Godse K, Krupa Shankar DS, Sanjiv K, et al. (2017) Diagnosis and Management of Chronic Pruritus: An Expert Consensus Review. Indian J Dermatol 62(1): 7-17.

16. Longley J, Duffy TP, Kohn S (1994) The mast cell and mast cell disease. J Am Acad Dermatol 32(4): 545-561.

17. Finley AY, Khan G K (1994) Dermatology Life Quality Index (DLQI)--A simple practical measure for routine clinical use. Clin Exp Dermatol 19(3): 210-216.

18. Finlay AY (2004) Quality of life indices. Indian J Dermatol Venereol Leprol 70(3): 143-148.

19. Kulthana K, Jiumton S, Wanitphakdeedecha R (2004) The Validity and Reliability of the Dermatology Life Quality Index (DLQI) in Thais. Thai J Dermatol 20: 113-123.

20. Ko MJ, Chiu HC, Jee SH, Hu FC, Tseng CH (2013) Postprandial blood glucose is associated with generalized pruritus in patients with type 2 diabetes. Eur J Dermatol 23(5): 688-693.

21. Chularojanamontri L, Sethabutra P, Kulthanan K, Manapajon A (2011) Dermatology life quality index in Thai patients with systemic sclerosis: A cross-sectional study. Indian J Dermatol Venereol Leprol 77(6): 683-637.

22. Lemeshow S, Hosmer DW, Klar J, Lwanga SK, Organization WH (1990) Adequacy of sample size in health studies. WHO?

23. Ständer S, Augustin M, Reich A, Blome C, Ebata T, et al. (2013) Pruritus assessment in clinical trials: consensus recommendations from the International Forum for the Study of Itch (IFSI) Special Interest Group Scoring Itch in Clinical Trials. Acta Derm Venereol 93(5): 509-514.

24. Batalla A, García Doval I, Peón G, de la Torre C (2013) A Quality-of-Life Study of Cutaneous Lupus Erythematosus. Actas Dermosifiliogr 104(9): 800-806.

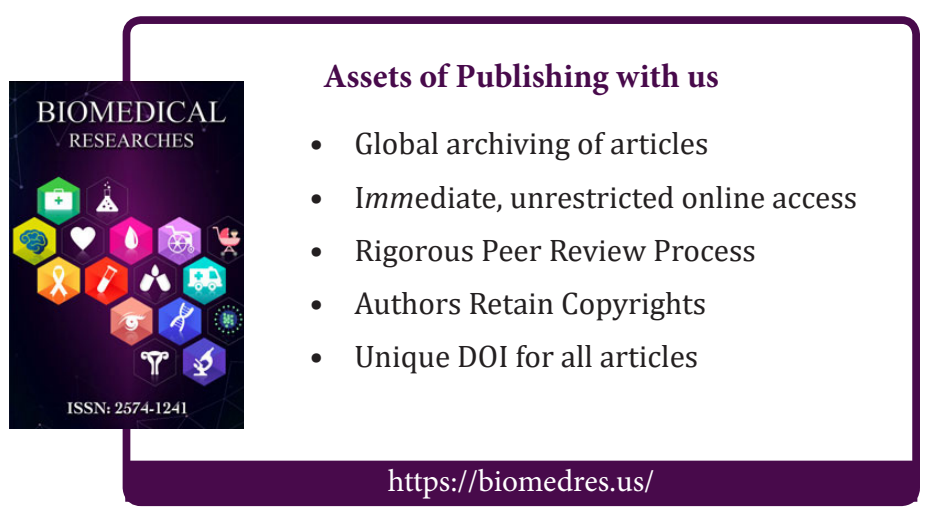

